American Journal of Immunology 6 (1): 1-6, 2010

ISSN 1553-619X

(C) 2010 Science Publications

\title{
Analysis of Salmonella enteritidis Outer Membrane Proteins and Lipopolysaccharide Profiles with the Detection of Immune Dominant Proteins
}

\author{
${ }^{1,2}$ A. Maripandi and ${ }^{2}$ Ali A. Al-Salamah \\ ${ }^{1}$ Department of Microbiology, KS Rangasamy College of Arts and Science, \\ Tiruchengode-637 209, Namakkal District, Tamil Nadu, India \\ ${ }^{2}$ Unit of Medical Bacteriology, Department of Botany and Microbiology, \\ College of Science, King Saud University, P.O. Box 2455, Riyadh, Saudi Arabia
}

\begin{abstract}
Problem statement: Salmonella infection is a serious medical and veterinary problem worldwide and causes great concern in the human health and food safety. Salmonella enteritidis outer membrane proteins and lipopolysaccharide play important role in the virulence and immunological properties of bacteria. Prophylaxis of enterobacterial infection has proven difficult to achieve. Vaccination is an effective tool for the prevention of Salmonella infection. Approach: Therefore, a study was conducted on $S$. enteritidis isolates from chicken meat samples for Outer Membrane Proteins (OMPs) and Lipopolysaccharide (LPS) profile were analyzed by SDS-PAGE electrophoresis and immunodominent antigen was detected by western blot analysis. Results: $S$. enteritidis with different OMPs bands were exhibited with molecular weight ranging from 5-90 kDa. The major outer membrane protein profiles of all $S$. enteritidis isolates were homogenous with different expression in intensity of protein was observed. LPS of different $S$. enteritidis isolates exhibited doublet band was observed and identified as R type of strains. The immunoblotting results at 14.4 and $24 \mathrm{KDa}$ proteins were good immunogen. Conclusion: The 14.4 and 24 KDa proteins were immune response protein. This proteins can use for vaccine development.
\end{abstract}

Key words: Salmonella enteritidis, outer membrane protein, immune-dominant antigen

\section{INTRODUCTION}

Salmonella enteritidis is a causative agent of major food-borne illness and life threading problem worldwide. Poultry products are known to be a significant reservoir for Salmonella and most important source in human infection (Maripandi and Al-Salamah, 2010). The World Health Organization (WHO) has estimated that annually 1.3 billion cases of acute gastroenteritis or diarrhea due to non typhoid salmonellosis occur with 3 million deaths. It is usually difficult to evaluate the situation of salmonellosis in developing countries because of the very limited scope of studies and lack of coordinated epidemiological surveillance systems (Acha and Szyfres, 2001). The relatedness of Salmonella isolates outer membrane proteins (Davies, 1991) and lipopolysaccharide profile (Threlfall and Chart, 1993) analyses have proved to be useful techniques in the characterization of these bacteria.

The currently available vaccines against salmonellosis can be divided into three major classes:
Bacterins, attenuated and subunit vaccines. Protection induced by bacterins in poultry is generally modest (Barbour et al., 1993; Gast et al., 1993). In humans, killed vaccines elicit good antibody responses but induce poor cell-mediated immunity, are reactogenic and confer a moderate degree of protection (Collins, 1974). Live attenuated vaccines have multiple advantages over nonviable vaccines because of their ease of administration, ability to carry heterologous antigens and capacity to induce mucosal, cellular and humoral immune responses. Live attenuated Salmonella vaccines offer varying degrees of protection in chickens (Cooper et al., 1996; Zhang-Barber et al., 1999). Acellular vaccines containing immune-dominant protein components of the bacteria may offer an alternative. The components of such subunit vaccine should be founded on the empirical data indicating that in animals and humans exposed to live Salmonella, long-lasting immunological memory are directed towards a broad spectrum of antigens, including lipopolysaccharide, outer-membrane proteins, flagellae epitopes and fimbriae. The present study was to

Corresponding Author: A. Maripandi, Unit of Medical Bacteriology, Department of Botany and Microbiology, College of Science, King Saud University, P.O. Box 2455, Riyadh, Saudi Arabia Tel: +966 546596472 
investigate Salmonella OMP and LPS profiling and to evaluate the antigenicity of the outer membrane proteins by western blot as an effective identification method for potent antigen protein detection. In future acellular vaccine development would be carried out with the help of immune-dominant proteins against poultry salmonellosis.

\section{MATERIALS AND METHODS}

Bacterial cultures and maintenance: Salmonella cultures were isolated from poultry meat samples. $S$. enteritidis isolates were identified by standard biochemical and serological methods (Cox and Williams, 1976). The cultures were stored at $4^{\circ} \mathrm{C}$ as stationary cultures on nutrient agar slants (Hi-Media, India) maintained at Microbiology Laboratory, KS Rangasamy College of Arts and Science College, Tiruchengode, Namakkal District, Tamilnadu, India for experimental studies. A total of twelve S. enteritidis isolates were used based on the antibiotic resistant patterns. For outer membrane protein and lipopolysaccharide profiles analyses, the isolates were subcultured on Luria Bertanii medium at $37^{\circ} \mathrm{C}$ for overnight on orbital shaker incubator.

Isolation of outer membrane proteins: The bacterial culture $(10 \mathrm{~mL})$ was taken and centrifuged at $3000 \mathrm{rpm}$ for $10 \mathrm{~min}$ at $4{ }^{\circ} \mathrm{C}$. The pellet was resuspended in $1000 \mu \mathrm{L}$ of phosphate buffer saline and washed twice. The washed pellet was resuspended in $1000 \mu \mathrm{L}$ of HEPES-KOH (0.25 M Sucrose $30 \mathrm{mM}$ HEPES $0.1 \mathrm{mM}$ $\mathrm{MgCl}_{2} 14 \mathrm{Mm} \quad \beta-(1.2 \mathrm{~mL}) \quad 0.1 \mathrm{mM}$ PMSF-Phenyl methane sulfonyl fluoride.) buffer. It was homogenized by sonication for $30 \mathrm{~min}$, centrifuged at $7000 \mathrm{rpm}$ for $15 \mathrm{~min}$ at $4^{\circ} \mathrm{C}$ and the supernatant was transferred to fresh tube, centrifuged $20,000 \mathrm{rpm}$ at $4^{\circ} \mathrm{C}$ for $30 \mathrm{~min}$. The supernatant was discarded and the membrane pellet was air dried. The membrane pellet was resuspended in $300 \mu \mathrm{L}$ of membrane extraction buffer (50 mM Tris HCL; $1 \mathrm{mM} \mathrm{NaCl} \mathrm{0;} 1 \mathrm{mM}$ PMSF; $8 \mathrm{M}$ Urea). It was incubated at room temperature for 1-2 $\mathrm{h}$ with occasional shaking. About $700 \mu \mathrm{L}$ of potassium buffer $(50 \mathrm{mM}$ $\mathrm{KH}_{2} \mathrm{PO}_{4} ; 1 \mathrm{mM}$ EDTA; $50 \mathrm{mM} \mathrm{NaCl} \mathrm{pH} \mathrm{10.7)} \mathrm{was}$ added for lysis of the mixture. The samples was incubated at room temperature for $30 \mathrm{~min}$ and centrifuged at $10,000 \mathrm{rpm}$ for $5 \mathrm{~min}$ at room temperature supernatant was transferred to fresh tube. By adding saturated $\left(\mathrm{NH}_{4}\right)_{2} \mathrm{SO}_{4}$, mixed well and allowed to precipitate at $4^{\circ} \mathrm{C}$ for $30 \mathrm{~min}$ and centrifuged at $12,000 \mathrm{rpm}$ for $20 \mathrm{~min}$ at $4^{\circ} \mathrm{C}$ thereby pellet was resuspended in $50 \mathrm{mM}$ sodium acetate $(\mathrm{pH}$ 4.5-5.5). Protein concentration was estimated by the method of Lowry et al. (1951). SDS-PAGE was performed under reducing conditions with the discontinuous buffer systems of Laemmli (1970).

Isolation of Lipopolysaccharides (LPS): The lipopolysaccharide extractions were prepared from whole cell lysates and also from outer membrane fractions. Whole cell lysates were prepared by adapting the methods of Hitchcock and Brown (1983). The Salmonella culture was inoculated in $50 \mathrm{~mL}$ of LB broth supplemented with $3 \%$ of $\mathrm{NaCl}$ and incubated at $37^{\circ} \mathrm{C}$ for $18 \mathrm{~h}$ on orbital shaker incubator. After the incubation the culture was centrifuged at $12000 \mathrm{rpm}$ for $15 \mathrm{~min}$, supernatant was discarded and pellet was allowed to dry. The dried pellet was washed with Phosphate Buffer Saline (PBS) for several times, after that the pellet was resuspended with $50 \mu \mathrm{L}$ of PBS. This resuspended pellet was mixed with equal volume of double concentrated electrophoresis (SDS-PAGE) sampling buffer and boiled for $10 \mathrm{~min}$ at $100^{\circ} \mathrm{C}$ in water bath. The sample were digested with $30 \mu \mathrm{L}$ of Proteinase $\mathrm{K}$, electrophoresis sample buffer $(0.25 \% \quad(\mathrm{w} / \mathrm{v}))$ (Laemmli, 1970) and boiled for $15 \mathrm{~min}$ at $60^{\circ} \mathrm{C}$ in water bath. After that the sample was loaded on to $1.5 \mathrm{~mm}$ $12.5 \%$ SDS-PAGE gel. The gel was stained for visualizing the lipopolysaccharides bands by the methods described by Tsai and Frasch (1982). The gel was removed from the plate and immersed in the fixative solution (Ethanol: Glacial acetic acid: Water) and incubated for 4-12 h. After the incubation, the fixative solution was discarded and the gel was transferred to $30 \%$ ethanol solution and incubated for $30 \mathrm{~min}$. The gel was put into distilled water and gently shaken for about $10 \mathrm{~min}$. Later the gel was put into a freshly prepared silver nitrate solution $(0.25 \%)$ and incubated in dark condition for $30 \mathrm{~min}$. After that the solution was discarded and the gel was rinsed with distilled water for several times. Then, the gel was kept in $2.5 \%$ sodium hydroxide solution and $0.02 \%$ formaldehyde solution till the bands of desired contrast were obtained.

Immunoblotting: Resolved antigens were electrohporetically transferred to nitrocellulose paper (0.45 mm pore size) using a blot apparatus (Towbin et al., 1979). The gels were soaked in transfer buffer (0.025 M Tris, pH 8.3 containing $0.192 \mathrm{Mg}$ lycine and $20 \%$ methanol) for $30 \mathrm{~min}$ and transfer was carried out at $50 \mathrm{~V}$ for overnight. The nitrocellulose sheets were used immediately or were stored at $4^{\circ} \mathrm{C}$. 
Incubating with blocking solution (2\% Skimmed milk powder) blocked non reactive sites of the nitrocellose. After washing with blocking buffer for 4 times at $3 \mathrm{~min}$ interval, the study was incubated overnight at $4^{\circ} \mathrm{C}$ with sera diluted in phosphate buffer saline tween. Antibodies bound were detected with Horseradish peroxides conjugated anti rabbit immunoglobulin's diluted 1:1000 at room temperature for $1 \mathrm{~h}$. After repeated washes, the strip were developed using $\mathrm{TMB} / \mathrm{H}_{2} \mathrm{O}_{2}$ as the substrate and was stopped by washing the membrane in distilled water. The molecular weights of the recognized bands were calculated with reference to the standard molecular weight marker.

\section{RESULTS}

Salmonella enteritidis OMPs analysis revealed that the different isolates of $S$. enteritidis showed uniform patterns and intensity of protein bands expression differ in different isolates. In isolate number 1, 2, 10 and 11 the OMP expression has been unique when compared to existing others $S$. enteritidis protein profiles. These isolates have been observed more expressed protein on $14 \mathrm{KDa}$. Whereas culture number 4 and 7 they have $90 \%$ similarities with the earlier mentioned isolates but they have been dissimilar in quantum of $14 \mathrm{KDa}$ protein appearances on the protein gel. On the other hand isolates 6 and 9 they expressed same protein profiles and rest of the $S$. enteritidis number 5, 3, 8 and 12 they have been differ from other isolated in the pattern of protein expression Fig. 1. All the isolates of $S$. enteritidis homogenous protein bands as intense protein bands in the range from 14 and $45 \mathrm{KDa}$ was a general character of the OMP preparation while fainter bands were revealed at the higher molecular weight end (higher than $45 \mathrm{KDa}$ ) as well as at the lower molecular weight end (lower than $14 \mathrm{KDa}$ ).

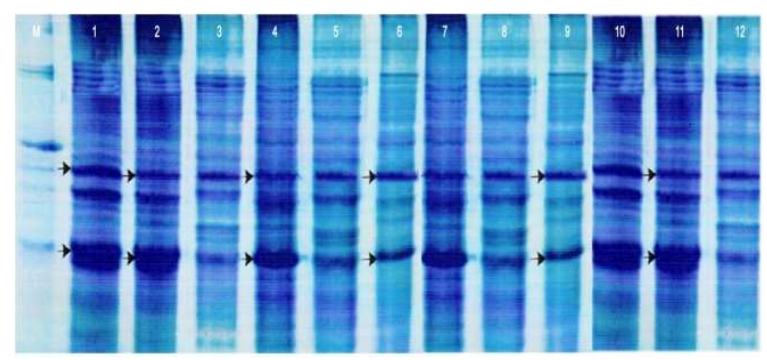

Fig. 1: Outer membrane protein profiles of Salmonella enteritidis isolates Lane M: Protein marker with molecular weight $94,66.2,45,31,21.5$ and 14.4 KDa and Lane 1-12 different isolates of S. enteritidis OMP expression profiles
The chicken isolates used for the OMP isolation were subjected to LPS analysis. The LPS were extracted from whole cells (grown at $37^{\circ} \mathrm{C}$ ) treated with proteins$\mathrm{K}$ and results were doublet from Fig. 2, which was identified as all the isolates were $\mathrm{R}$ type strains. The western blot analysis was carried out against OMP of S. enteritidis, serum antibodies from chicken infected with $S$. enteritidis reacted with protein band at 14.4 and 24 KDa while non-infected chicken with $S$. enteritidis were non-reactive with any protein band Fig. 3, based on which the reacted proteins were identified as immuno-dominant antigen.

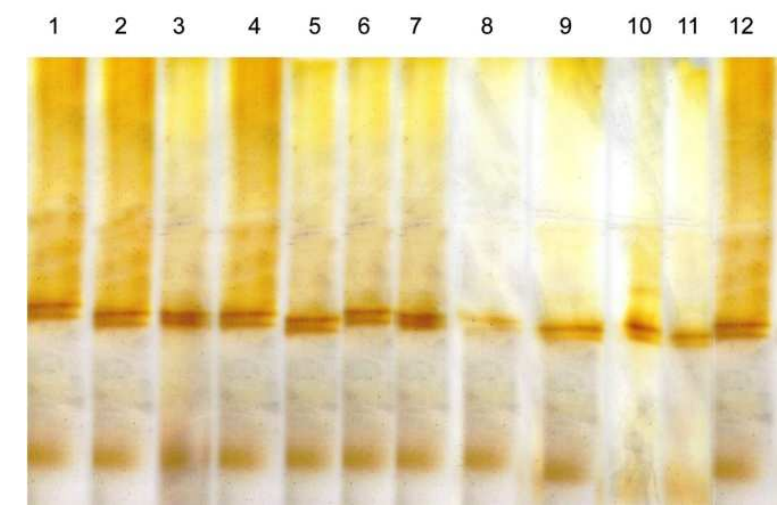

Fig. 2: Lipopolysaccharide expression profile of $S$. enteritidis with doublet appearance by silver staining

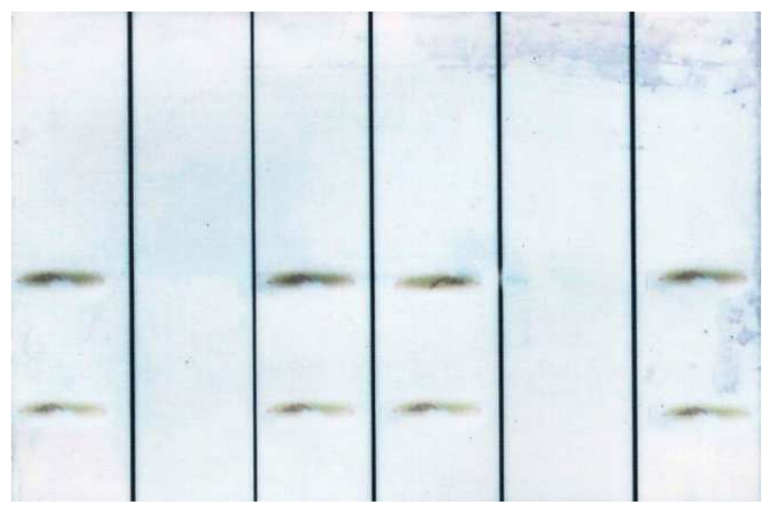

Fig. 3: Immunoblot analysis of antisera from immunized chicken with OMPs of S. enteritidis. Lane 1, 3, 4 and 6 OMPs of $S$. enteritidis reacted with immunized chicken sera at 14 and $24 \mathrm{KDa}$. Lane 2 and 5 uninfected chicken sera not reacted with OMPs of S. enteritidis 


\section{DISCUSSION}

Salmonella infection is a serious medical and veterinary problem world-wide and causes great concern in the food industry. Fowl typhoid (Salmonella gallinarum) and Pullorum disease (S. pullorum) remain to cause economic losses in many countries (Mastroeni and Menager, 2003). Prevention of the disease by implementation of hygienic measures is possible but difficult. Now-a-days $S$. enteritidis develop a multidrug resistance to many of the antibiotics. In future, application of antibiotics for treatment will become less common. The possible treatment and preventive approach may include recombinant vaccines, peptide library screening and adhesion receptor interaction studies. Prophylaxis of enter bacterial infection has proven difficult to achieve. Vaccination is an effective tool for the prevention of Salmonella infection. However, efficacy of currently available vaccines is not always enough (Mastroeni and Menager, 2003). Despite numerous attempts at vaccine development, the only recognized vaccine still is the Salmonella vaccine consisting of whole killed bacteria. Even this vaccine is not satisfactory the protections given is incomplete and of short duration and adverse effects due to toxicity of lipopolysaccharide are always same. Development of vaccine based on defined nontoxic, components of these bacteria would therefore seem desirable.

Vaccines prepared from outer membrane proteins of $S$. enterica have been promising in experiment. The outer membrane of gram negative bacteria, in addition to lipopolysaccharides and lipids contains several proteins which represent integral proteins of the bacterial outer membrane. The OMP electrophoresis analysis of $S$. enteritidis showed that many protein bands which constitute the common genus antigen. The intense protein region which occupied the range from 14 and $45 \mathrm{KDa}$ constituted the Salmonella specific OMP bands. The fainter bands which were revealed at the higher molecular weight region (higher than $45 \mathrm{KDa})$ and at the lower molecular weight region (lower than $14 \mathrm{KDa}$ ) were bands related or associated to the OMP or residues of flagella and pilus protein (lower than $20 \mathrm{KDa}$ ) or could be residues of Salmonella toxins (higher than $67 \mathrm{KDa}$ ). OMP preparation from $S$. enteritidis showed greater similarities in their electrophoretic patterns and expression of protein intensity bands were different Fig. 1. Similar type of results reported by Chart and Rowe (1991) demonstrated three major OMPs of 33, 35 and $36 \mathrm{KDa}$ in three $S$. enteritidis strains and one $S$. typhimurium strain. The results revealed that the majority of S. typhimurium isolates $(74.3 \%)$ contained two OMPs of 30.6 and $34.6 \mathrm{kD}$. Six isolates $(17.1 \%)$ carried three OMPs of 27.2, 30.6 and $34.6 \mathrm{KDa}$ and three isolates $(8.6 \%)$ contained only a $30.6 \mathrm{KDa}$ OMP. On the other hand, Helmuth et al. (1985) who found that $S$. typhimurium strains generally contained OMPs of 37 and 40 and $41.7 \mathrm{KDa}$.

In our study $S$. enteritidis lipopolysaccharde analysis showed golden yellow doublet bands when performed silver staining and characteristic of $\mathrm{R}$ type strains. Although similar type of results were observed by Hitchcock and Brown (1983) has classified this type of strain as $\mathrm{R}$ type (with doublet band) in addition to another S. typhi with ladder like lipopolysaccharde. $S$. enteritidis the diversity exhibited by the isolates in terms of OMP should be considered. In the western blot analysis carried out against OMP of S. enteritidis, serum antibodies from chicken infected with $S$. enteritidis reacted with protein band at molecular weight 14.4 and $24 \mathrm{KDa}$. Similar findings were reported by Zamora et al. (1999). Antibodies raised against $S$. typhimurium reacted with protein bands at molecular weights of 17, 24 and $31 \mathrm{KDa}$. This range of protein bands have been claimed as the major outer membrane protein of S. typhimurium. In another study involving natural infection of hen with $S$. enteritidis reported by Javier et al. (2004) they observed that the higher frequency of reactants of naturally infected hen sera against OMP of $21.1 \mathrm{KDa}(66.2 \%)$. A reaction against the other OMP defined by its molecular weight was observed between 50.0 and $63.5 \%$, in contrast to low percentage of seropositivity against rest of the components $(14,6.6 \%$; SEF 21, 3.3\%; OMP A, 6.7\%; Flagella, $0.0 \%$ ) These results suggest that there is a specific reactivity of sera from naturally infected hens with $S$. enteritidis against SEFs, OMP A and Flagella. The unidentified OMPs with apparent molecular masses of 30.5, 35.8, 41 and 55, may correspond with some of the major antigenic protein from whole cells of S. enteritidis described by Barbour et al. (2000). The immunogenicity of these components during the natural infection would indicate their possible role as inductive antigens in a sub cellular vaccine for its use in poultry.

In order to control and stop the losses incurred by Salmonella in chicken formalin killed Salmonella bacterins has been used commercially in the field in many areas of the world (Wray and Sojka, 1984). Yet out of these result we could conclude that Salmonella OMP can play an essential role in the induction of immune response in the animals and can be employed as an effective candidate vaccine which can confer solid and active immunity and evade the hefty expenses of treatment of Salmonella infected which 
lately has acquired multiple potent antibiotic resistance (Carlson et al., 2002; Donkersgoed et al., 1999; Galland et al., 2000).

\section{CONCLUSION}

In conclusion, our finding highlighted the OMPs of 14.4 and $24 \mathrm{KDa}$ protein of $\mathrm{S}$. enteritidis could immune-response proteins. This proteins can use for vaccine preparation in future. It containing immunedominant protein components of the bacteria may offer an alternative to an existing vaccine which control the salmonellosis in human and animals.

\section{REFERENCES}

Acha, P.N. and B. Szyfres, 2001. Zoonoses and Communicable Diseases Common to Man and Animal: Bacterioses and Mycoses. 3rd Edn., Pan American Health Organization, ISBN: 927531580 9, pp: 361.

Barbour, E.K., W.M. Frerichs, N.H. Nabbut, P.E. Poss and M.K. Brinton, 1993. Evaluation of bacterins containing three predominant phage types of Salmonella enteritidis for prevention of infection in egg-laying chickens. Am. J. Vet. Res., 54: 1306-1309. PMID: 8214901.

Barbour, E.K., E.I. Jurdi, L.H. Faroo, O.M. Daghir and M. Bouljihad, 2000. Chronological recognition by chicken of antigenic polypeptides in Salmonella enteritidis with different plasmid profiles: Relationship to infection rate. J. Vet. Med. Sci., 62: 565-570. PMID: 10907680

Carlson, S.A., W.C. Stoffregen and B.R. Bolin, 2002. Abomasitis associated with multiple antibiotic resistant Salmonella enterica serotype Typhimurium phage type DT104. Vet. Microbiol., 85: 233-240. DOI: 10.1016/S0378-1135(01)00508-9

Chart, H. and B. Rowe, 1991. Antibodies to lipopolysaccharides and outer membrane proteins of Salmonella enteritidis PT4 are not involved in protection from experimental infection. FEMS Microbiol. Lett., 84: 345-350. PMID: 1804766.

Collins, F.M., 1974. Vaccines and cell-mediated immunity. Bacteriol. Revi., 38: 371-402. PMID: PMC413869

Cooper, G.L., L.M. Venables and M.S. Lever, 1996. Airborne challenge of chickens vaccinated orally with the genetically-defined Salmonella enteritidis aroA strain CVL30. Vet. Rec., 139: 447-448. PMID: 8931302

Cox, N.A. and J.E. Williams, 1976. A simplified biochemical system to screen Salmonella isolates from poultry for serotyping. Poult. Sci., 55: 1968-1971. PMID: 995819
Davies, R.L., 1991. Outer membrane protein profiles of Yersinia ruckeri. Vet. Microbiol., 26: 125-140. PMID: 2024435

Donkersgoed, J.V., T. Graham and V. Ganon, 1999. The prevalence of verotoxins. Escherichia coli, 0157: H7 and Salmonella in the faces and human of cattle at processing. Can. Vet. J., 40: 332-338. PMID: PMC1539799

Galland, J.C., J.K. House, D.R. Hyatt, L.L. Hawkins and B.P. Smith, 2000. Prevalence of Salmonella in beef feeder steers as determination by bacterial culture and ELISA serology. Vet. Microbiol., 76: 143-151. DOI: 10.1016/S0378-1135(00)00230-3

Gast, R.K., H.D. Stone and P.S. Holt, 1993. Evaluation of the efficacy of oil-emulsion bacterins for reducing fecal shedding of Salmonella enteritidis by laying hens. Avian Dis., 37: 1085-1091. http://www.jstor.org/pss/1591918

Helmuth, R., R. Stephan, C. Bunge, B. Hoog and A. Steinbeck et al., 1985. Epidemiology of virulence associated plasmids and outer membrane protein patterns within seven common Salmonella serovars. Infect. Immun., 48: 175-182. http://iai.asm.org/cgi/content/abstract/48/1/175

Hitchcock, P.J. and T.M. Brown, 1983. Morphological heterogenecity among Salmonella lipopolysaccharide chemotypes in silver-stained poly acrylamide gels. J. Bacteriol., 54: 227-269. PMID: 6187729

Javier, O.R., S. Begona, A. Miguel, M.J. Renedo and J.M. Irache et al., 2004. Humoral immune response in hens naturally infected with Salmonella enteritidis against outer membrane proteins and other surface structural antigens. Vet. Res., 35: 291-298. PMID: 15210078

Laemmli, U.K., 1970. Cleavage of structural proteins during the assembly of the head of bacteriophage $\mathrm{T}_{4}$. Nature, 227: 680-685. http://www.nature.com/nature/journal/v227/n5259/ abs $/ 227680$

Lowry, C.H., N.J. Rosebrough and A.L. Farr, 1951. Protein measurement with the folin phenol reagent. J. Biol. Chem., 93: 266-275. http://www.jbc.org/content/193/1/265

Maripandi, A. and A.A. Al-Salamah, 2010. Multipleantibiotic resistance and plasmid profiles of Salmonella enteritidis isolated from retail chicken meats. Am. J. Food Technol., 5: 260-268. DOI: ajft.2010.260.268

Mastroeni, P. and N. Menager, 2003. Development of acquired immunity to Salmonella. J. Med. Microbiol., 52: 453-459. DOI: 10.1099/jmm.0.05173-0 
Threlfall, E.J. and H. Chart, 1993. Interrelationships between strains of Salmonella enteritidis. Epidemiol. Infect., 11: 1-8. DOI: 10.1017/S0950268800056612

Towbin, H., T. Stachelin and J. Gordon, 1979. Electrophoretic transfer of proteins from polyacrylamide gels to nitrocellulose sheets: Procedure and some application. PNAS, 76: 4350-4354. PMID: 388439

Tsai, C.M. and C.E. Frasch, 1982. A sensitive silver stain for detecting lipopolysaccharide in polyacrylamide gels. Anal. Biochem., 199: 115-119. DOI: 10.1016/0003-2697(82)90673-X
Wray, C. and W.J. Sojka, 1984. The serological response of calves to live Salmonella dublin Vaccine, a comparison of different serological tests. J. Biolog. Standard., 12: 277-282. DOI: 10.1016/S0092-1157(84)80007-4

Zamora, B.M., M. Hartung and G. Hildebrant, 1999. Simplified preparation of a specific Salmonella enteritidis antigen for ELISA and other serological techniques. J. Vet. Med., 46: 1-7. DOI: 10.1046/j.1439-0450.1999.00189.x

Zhang-Barber, L., A.K. Turner and P.A. Barrow, 1999. Vaccination for control of Salmonella in poultry. Vaccine, 17: 2538-2545. DOI: 10.1016/S0264410x(99)00060-2 